\title{
TeACHING From 1 to 9: A Progressive TeACHING AND LEARNING EXPERIENCE
}

\author{
Mohamed Ismail \\ Industrial Systems Engineering, University of Regina \\ mohamed.ismail@uregina.ca
}

\begin{abstract}
The peak quality of teaching and learning experience cannot be developed or fostered overnight; however, adopting a course design and delivery framework is instrumental in achieving such a level of peak quality at the teaching and learning process. This paper introduces a novel double-loop course design and delivery process and overall syllabus and course design framework that has been developed over the years and achieved great popularity among many engineering students. Over the time, a unified course design and delivery framework that encapsulate long lists of best practices have been developed which will be described in detail in this paper. A software tool for unified course design called Touch-it, a data-driven course analytics system, and grade reporting systems that augment the proposed framework will be highlighted as well. The experience reported should be useful for early career instructors or those who might be struggling in their teaching career.
\end{abstract}

Keywords: Engineering Education; Course Design; Outcome-Based Assessment

\section{INTRODUCTION}

The peak quality of teaching and learning experience cannot be developed or fostered overnight; however, adopting a course design and delivery framework is instrumental in achieving such a level of peak quality at the teaching and learning process. This paper introduces a novel double-loop course design and delivery process and overall syllabus and course design framework that has been developed over the years and achieved great popularity among many engineering students. Over the time, a unified course design and delivery framework and best practices have been developed and will be described in detail in this paper. A software tool for unified course design called Touch-it, a data-driven course analytics system, and grade reporting systems that augment the proposed framework will be highlighted as well. The experience reported should be useful for early career instructors or those who might be struggling in their teaching career.

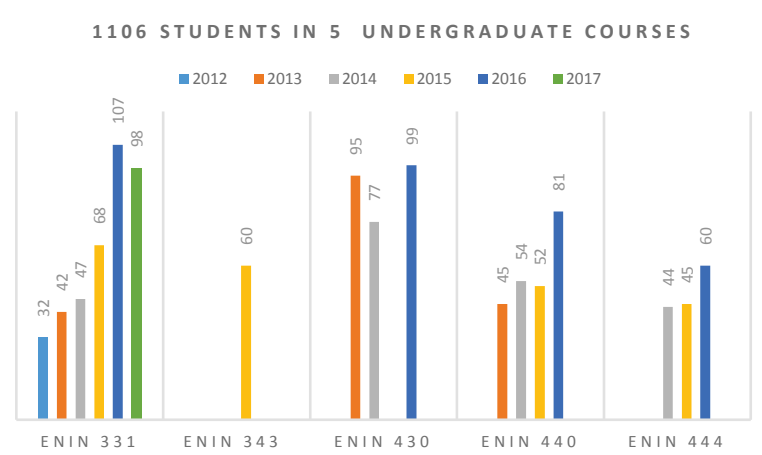

Figure 1: 5 undergraduate courses from 2012-2017, enrolment and year taught. The frequency ranges from just one time to six times

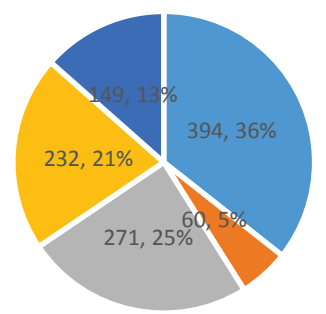

- ENIN 331 -ENIN 343 -ENIN 430 - ENIN 440 - ENIN 444

Figure 2: 5 undergraduate courses from 2012-2017: total enrollment are and percentages

114 STUDENTS IN 4 GRADUATE COURSES

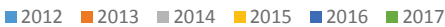

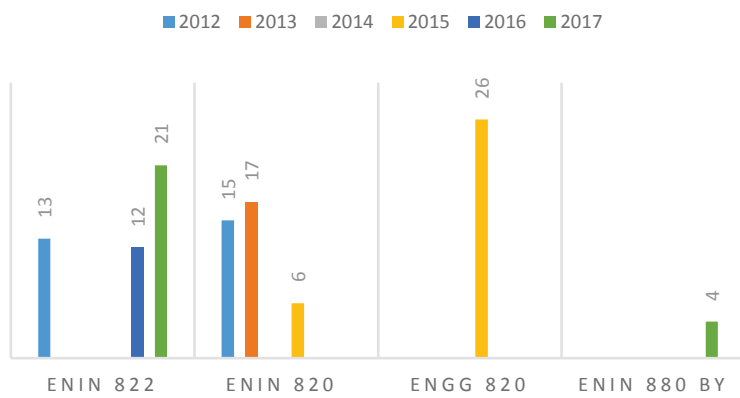

Figure 3: 4 Graduate courses from 2012-2017 
Table 1: 9 courses from 2012-2017

\begin{tabular}{llll}
\hline Course \# & \multicolumn{1}{c}{ Course Name } & \multicolumn{1}{c}{ Notes on success/failure } \\
\hline 1 ENIN 820 & Manufacturing Systems & Persistent success \\
\hline 2 ENIN 331 & Modeling and Simulation of Industrial Systems & Persistent success from 2012-2015, large class struggle in 2016 and 2017 & Persistent success \\
\hline 3 ENIN 822 & Stochastic Systems Simulation & Struggle in 2013, 2014, massive success in 2016 \\
\hline 4 ENIN 430 & Systems Management & Struggle in 2013, 2014, massive success in 2015 \\
\hline 5 ENIN 440 & Statistical Quality Control & Persistent success from 2014-2015, large class struggle in 2016 \\
\hline 6 ENIN 444 & CAD/CAM and CAE Systems & Massive success for the only one time experience \\
\hline 7 ENIN 343 & Manufacturing Processes and Machinery & Success for the only one time experience \\
\hline & ENGG 820 & Engineering Economy for Practicing Engineers & Success for the only one time experience \\
\hline
\end{tabular}

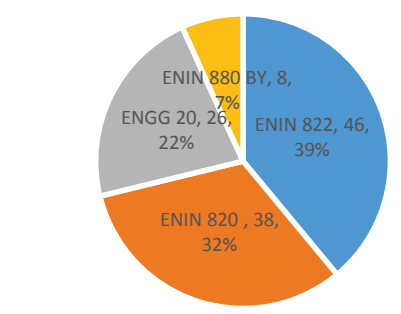

- ENIN 822 - ENIN 820 - ENGG 20 = ENIN 880 BY

Figure 4: Enrollment (numbers and percentages)

In 2011, the year I defended my $\mathrm{PhD}$ [1] at the University of Windsor ( $U$ of $\mathrm{W}$ ), I had an excellent chance to join a series of university teaching courses and workshops at the Center for Teaching and Learning and the University Teaching Certificate (UTC) program at the U of W, Figure 5. During my PhD, I developed a new modeling approach called Progressive Modeling (PM). To formalize the modeling process, the process first version was a simplified 3-steps process. That first version was developed by the end of 2008 and got published in 2009 [2]. By the summer of 2011, the fourth generation 5-step double loop version came to existence. After joining the teaching dossier academy workshop at $\mathrm{U}$ of $\mathrm{W}$ in June

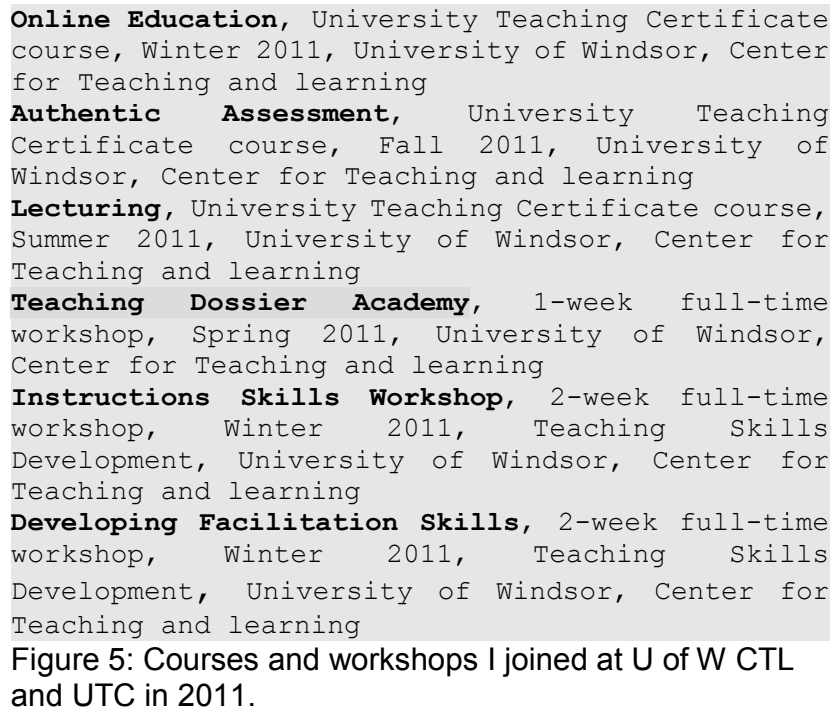

2011, I developed my first draft of the progressive teaching and learning project. The PM 5-step double-loop process was redefined to suit the teaching and learning environment, see Figure 6. The teaching dossier academy workshop was a turning point. I developed the first draft of my progressive teaching and learning project (PTL) at that time which was some reflections of how I would like to apply my progressive modeling process to my teaching experience/philosophy.

During the teaching dossier academy, my CTL mentors helped me to refine my teaching philosophy. They had a brief idea of the new modeling approach and its governing iterative process. During the last day of that workshop, a main comment came by one of my mentors and reiterated by the VP academic of U of W, "he is an engineer, he is an engineer, he is an engineer." Those words were a great boost for my vision of engineering the engineering education using PM guidelines. The PTL project started since then and it was part of my application for academic jobs. In summer 2011, I applied for an assistant professor job at U of R. On November $30^{\text {th }}$, I got the job offer, and in Jan 2012, I started implementing my PTL project.

Since I started my career in Jan 2012, I have taught 4 graduate courses and 5 undergraduate courses. My undergraduate courses include ENIN 331 Modeling and Simulation of Industrial Systems, ENIN 343 Manufacturing Processes and Machinery, ENIN 430 Systems Management, ENIN 444 CAD/CAM Systems, and ENIN 440 Statistical Quality Control. My graduate courses include ENIN 820 Manufacturing Systems, ENIN 822 Stochastic Systems Simulation, ENGG 820 Engineering Economy for Practicing Engineers, and the last but not the least is ENIN 880 BY Advanced Topics in Manufacturing Systems Analysis and Design.

Teaching graduate classes have some similarities and some differences from their undergraduate counterparts: Graduate students want to think pragmatically and in an open-ended fashion. They have many experiences that they want to share and are looking for open-ended questions and research-oriented activities. Graduate courses enjoyed the huge advantage of small class size, usually less than 20 . Course improvements happened as part of regular course review and improvement process. Graduate teaching for me was always like surfing on a calm day. No big issues, no serious calls for radical actions. 
On the other hand, the undergraduate students are looking more for undersetting and learning engineering concepts and how to implement them in a real-world setup. Now I'm considering myself lucky to have all my classes as third-, and fourth-year courses and graduate classes but in the past, it was struggling experience. In Winter 2013 and Winter 2014, I got harsh evaluations and comments for ENIN 430 and ENIN 440 courses, and I found a radical turn-around plan is needed despite the incremental improvements.

Until that time, my teaching portfolio included three undergraduates (ENIN 331, ENIN 430, and ENIN 440) and two graduates (ENIN 822 and ENIN 820). ENIN 331 and the graduate courses were very good from the first time I taught them. ENIN 430 and ENIN 440 were not good (a little bit below the faculty average).

The first decision was to drop ENIN 430. It has a large number of students $(\sim 90)$, and it has no lab. I replaced ENIN 430 with ENIN 444 despite its difficulty. I decided to keep ENIN 440. I decided to upgrade my teaching methodology and refine the progressive teaching and learning project to reflect all my best practices. In this paper, the updated version of PTL or PTL 2.0, best practices, and tools developed are shared in the remaining section of the paper.

In the fall of 2014, ENIN 444 was designed accordingly, and ENIN 331 was upgraded according to PTL 2.0 process and best practices framework. In December 2014, I started working on developing my outcome-based assessment and continuous improvement system (OBACIS). The first two artifacts were OBACIS data-driven course improvement (DDCI) system and OBACIS accreditation and grading sheets. The former used to analyze the performance of my students in ENIN 440, and through the tri-reporting system, I learned where my students fail and where they succeed. To the best of my knowledge, that was the first data-driven course improvement tool.

With PTL 2.0 and OBACIS DDCI, all my courses had top rating course evaluations, my classes witnessed the highest levels of class enrollments, and I became one of the most highly rated professors by all engineering students.

In 2015, I wanted to get back to ENIN 430 to fix its score and test my new methodology for a course that could be taught by me even for once (ENIN 343). However, there was a challenge, developing or fixing courses will take time and Touch-it( $\mathrm{C}$ was the solution. Touch-it is a PowerPoint add-in that I developed to cut down the course development cycle to less than three weeks. Touch-it(C) logic was developed to automate my course design methodology and make it unified across all my courses.

In the fall of 2015/2016, I taught 5 undergrads (ENIN 331, ENIN 444, ENIN 343, ENIN 430 and ENIN 440) and two graduate courses back to back. The scores were recorded high and the comments haven't been seen in a couple of decades as I have learned from my program head and later our associate dean research, thanks to the PTL 2.0, OBACIS artifacts, and Touch-itC.

In 2016 and due to the oil crash, the ISE witnessed a massive migration from petroleum systems engineering students, the class size soared high, and I got into some logistical trouble. By now most of the issues have been solved, and some lessons/best practices have developed to handle large classes issues.

In this paper, I will focus on the process that I developed, the best practices, and highlight some innovative tools and some techniques that worth sharing. Section 2 presents the double loop process. Section 3 presents the framework. Section 4 presents the two major OBACIS artifacts. Section 5 briefly describes the Touch-it Software. Section 6 concludes the paper.

\section{PROGRESSIVE TEACHING AND LEARNING PROJECT-THE $\infty$ PROCESS}

The progressive teaching and learning process represents a methodology where teaching technologies, pedagogical techniques, and best design and delivery practices are utilized throughout the teaching and learning experience. The process could be summarized in the following 5-steps double-loop process.

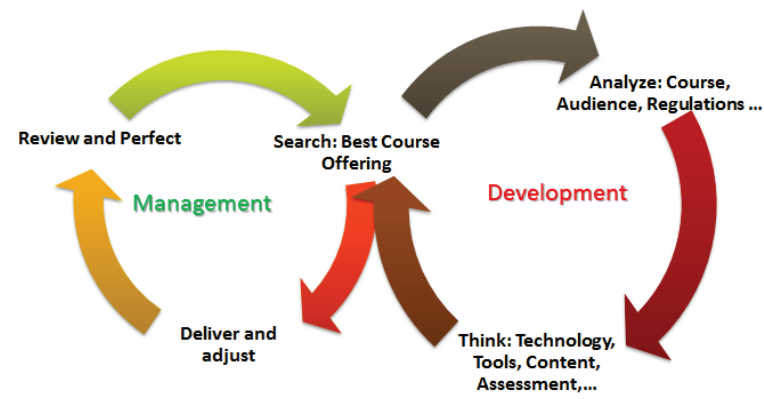

Figure 6: Progressive Teaching and learning Processthe $\infty$ process

1. Analyze: in the analytical stage, the course, the target audience, and the regulations, senates and bylaws, etc. are all reviewed, and all supporting course materials, teaching tools, methods are screened.

2. Think about technology, tools, content etc.: in this stage, the teaching process is personalized. The logic that governs is reduced to the strategies that an instructor may know and is going to implement, the teaching philosophy, the teaching experiences, the assessment tools, and any other related activities that an instructor might use.

3. Choose the best alternative: deciding on the best mix that will achieve the job and on compiling, authoring, and preparing all the course specifications and course materials that should make the best content to be delivered. Steps 1 to 
3 are repeatedly iterated until course syllabus, course lectures, assignments, projects, etc. are designed and ready to be delivered.

4. Respond to feedback and adapt: Now that the teaching and learning process is in action, an instructor is connected to students, engaged in what should work and what should not, and learning from past experiences, both the good and the bad ones. An instructor may go back to reiterate steps 1-3 if radical changes are needed.

5. Document and review: in this stage, the course experience is documented for immediate and future reviews. All the course materials, students' unsolicited feedback, peer review, any problems encountered and how they could be solved, etc. Logging and reviewing course activities are important for course development and accumulating experience from one year to the next.

Regardless of the course being taught, the infinity process remains the same. The two loops of the $\infty$-process represent a balance between designing/developing a course and managing its incremental development and delivery.

The double loop process has been there and implemented since I joined U of R in Jan 2012. Course evaluations provided typical testimonials of the long run success of the process. The process should be instructor independent. During the management phase minor adjustments are sometimes required. Every year while a certain course is being retaught, the process is repeated.

While ENIN 331 represents a first-time course design that witnessed incremental improvements, ENIN 440 and 430 witnessed radical changes in redesigning and adapting those courses entirely. The process of continuously redesigning and improving the courses led to the unified course design system that proved later its success even in newer courses such as ENIN 444 and ENIN 343.

\section{THE UNIFIED COURSE DESIGN AND DELIVERY SYSTEM AND THE $\infty$ - PROCESS}

\subsection{The Anatomy of Unified Syllabus:}

Course syllabus is an instrumental document in delivering quality teaching. The course syllabus anatomy described in this paper is what I have developed over the years and proved its effectiveness. All my course syllabi have the same unique course syllabus design that include the following sections: 1) course title 2) instructor, lab instructor, and teaching assistant info: names, phones, emails, offices, office hours etc. 3) Course description that might extend the academic calendar description 4) detailed list of learning outcomes 5) Expectations and responsibilities 6) Policies and Restrictions 7)
Professionalism and academic honesty practices 7) Course prerequisites, main textbook and other references 8) Estimated learning hours, learning experiences and teaching methods 9) Assessment and evaluation schemes 10) Detailed course outline which provides the content to be delivered, the timing, the corresponding textbook chapters, and the accompanying course assessment and course activities: assignments, projects, and case studies 11) any major course arrangements or announcements.

\subsection{Delivery Methods}

All my class lectures are delivered in PowerPoint Presentations. Presentations have also structured anatomy that have been developed throughout the years to be more effective and more helpful to my students. Every presentation starts with topics slide that demonstrate what to be presented, followed by several sections that divide the lecture into small gulps of content. Those sections represent milestones where I make sure that all students are comfortable with the content and the concepts behind. The sections also give the flexibility to stop the lecture at a good dividing point and allow me to extend or contract the time required to deliver a certain part of the lecture. My lectures are always rich in examples which have their own unique layout design that differentiate them from other concepts' slides. At the end of every lecture, there is always a summary slide or slides that keep reminding the student with the main concepts presented in the lecture.

PowerPoint slides are usually rich in terms of appealing design, animations, dynamic switching to larger views that enable me to view some details especially for complex illustrations, and embedded video content. During my early days I used to count on PowerPoint heavily in delivering my lecture but experience taught me that students like the classical whiteboard delivery more and it helps them to understand the concepts much easier. When they go home the course slides help them more to study especially for assignments and exams purposes. Currently, my method of lecture delivery is a hybrid of PowerPoint slides, digital content, and whiteboard class notes. My current delivery method is working at best and usually is praised by the majority of my students.

\subsection{Bridging, Engaging, and Sharing the Industrial Experiences}

Part of my success in my teaching career is engaging my students in what I am teaching and linking to the real world and how it is going to affect them in their future. Students easily get bored both at lecture and throughout the teaching semester. Some of the great lessons that I learned while joining the CTL and UTC courses and workshops is to get your students engaged first and makes them passionate about what they are going to learn second. Students love to share my industrial experiences, success and failure stories of engineering projects, product evolutions, rise and fall of 
companies, entrepreneurial stories, talking about exams and problem tips and tricks, the mistakes committed by their colleagues and how they can avoid it and get better marks, etc. Keeping students engaged within one lecture and throughout the entire teaching semester is a skill that I believe that it is getting honed and paying more benefits for my students and me as I move from one course to another and from one semester to another.

\subsection{Multiple Exam Versions, Unified Cheating Sheets, and Assessment Rubrics}

Exams are the fairest tool of assessment. Exams could be scheduled at a class time or at a different time. Cheating could be a concern, and if it happens, there could be a lot of consequences. Having Multiple exam versions has always been a good practice.

From day one I started teaching at $U$ of R, I always have multiple versions of my exam which eliminate radically many possibilities of cheating, reduces the number of invigilators, and facilitate having my exams especially the mid-terms conducted in the same lecture rooms.

Cheating sheets created a lot of headache in my early years of teaching. To eliminate those problems, every course I'm teaching weather its undergraduate or graduate has its own cheating sheet(s).

Three out of 5 undergraduate classes and all my graduate courses have project components. In addition to the detailed project description, assessment rubrics are provided to describe in detail the expectations to be delivered and how it's going to be assessed. Adopting rubrics make the assessment process fairer and improve the external learning outcomes sought from providing course projects.

\subsection{Office Hours and Direct Help to Students}

In addition to having regular office hours I usually make myself available to my students especially during course critical times.

Dedicated Project Office Hours: While working on their associated course projects (ENIN 331, ENIN 430, ENIN 444 , and all graduate ones), I offer my students extra office hours [1 hr a day] all the week long for the last week or couple of weeks before the project deadline to assist them in project consulting and on spot feedback for their project related activities.

Post Exam Review Sessions: I usually post my grades on UR courses ( $U$ of $R$ learning management system) even for the final exam and offer my students a 2-hrs review session for those who are concerned with their final grades. This helps a lot in eliminating any mistakes that could have happened during grading, open an opportunity for student counseling and reduces or eliminates any request for course reassessment.
Last Minute Review Sessions: The fall of 2014 witnessed a first-time last-minute sessions which had a very positive impact on my students and it has been repeated since then. Course Review Lecture: Now it becomes a habit for me, and a regular expectation from my students, to dedicate the last lecture or extra arranged lecture before the final to review my courses and give them some hints about exam format and exam expectations. Final exams usually have a tight schedule; providing the last review session is a sort of stress relief for students. One of the lessons that took me some time to realize.

\subsection{Large Classes}

Despite the massive success of PTL 2 and the associated tools developed, the dramatic rise in the ISE enrolment in 2016 and 2017 brought a new set of challenges that needed some course of actions.

The number of the TAs tripled, the number of invigilators needed was raised by an order of magnitude, the labs taught were doubled, exam marking became more challenging and having the TAs involved in marking became a rising issue. More office hours were needed, an inventory of emails was waiting for immediate replies, scheduling the exam for all students on the same day became a concern. It took a while until we managed to sort out most of these problems. Some best practices include 1) reduce the workload by making lectures available from day one; 2) carefully select your TAs; 3 ) conduct exam at the best time where a plenty of space could be available; late hours or a weekend if the latter is not possible; 4) develop exam multi-stage review sessions: TAs first then the instructor; 5) Get email notification from the LMS system direct to the main email account.

\subsection{Course Evaluations, the Negative Comments, and the Golden Rule}

Course evaluation are instrumental in closing the loop and identifying the possible opportunities for continual course improvement. Before developing the OBACIS DDCI system, course evaluation was my main source of improving my courses. Positive comments usually make us happy about our job, negative ones might be hurting sometimes. Negative comments should be easily treated and should never intimidate us from getting better. "Negative comments may have assignable causes, or may not or maybe they are just their for natural variability. You act only for the first, dump the rest". A golden rule learnt from teaching ENIN 440: Statistical Quality Control. 


\section{OBACIS DDCI AND AGS}

\subsection{OBACIS DDCI}

By the end of Fall of 2014 and developing, I was sure that PTL 2.0 practices need a better tool. Since I joined U of R, I had the intention to develop a software tool for outcomebased accreditation. The main challenge was the new $\mathrm{CEAB}$ graduate attributes, and the data-driven continues improvement system [3-5]. Many accreditation papers raised the issue of data-driven continuous improvement.

I found if there should be data-driven continuous improvement mechanism, it should be there at the classroom and at the course level first. OBACIS DDCI and the tri-reporting system was developed in less than two month, see Figure 7 and my CEEA 2016 first OBACIS publication for further details [6]. ENIN 440 in Winter 2015 was the first course to use DDCI tool, followed by
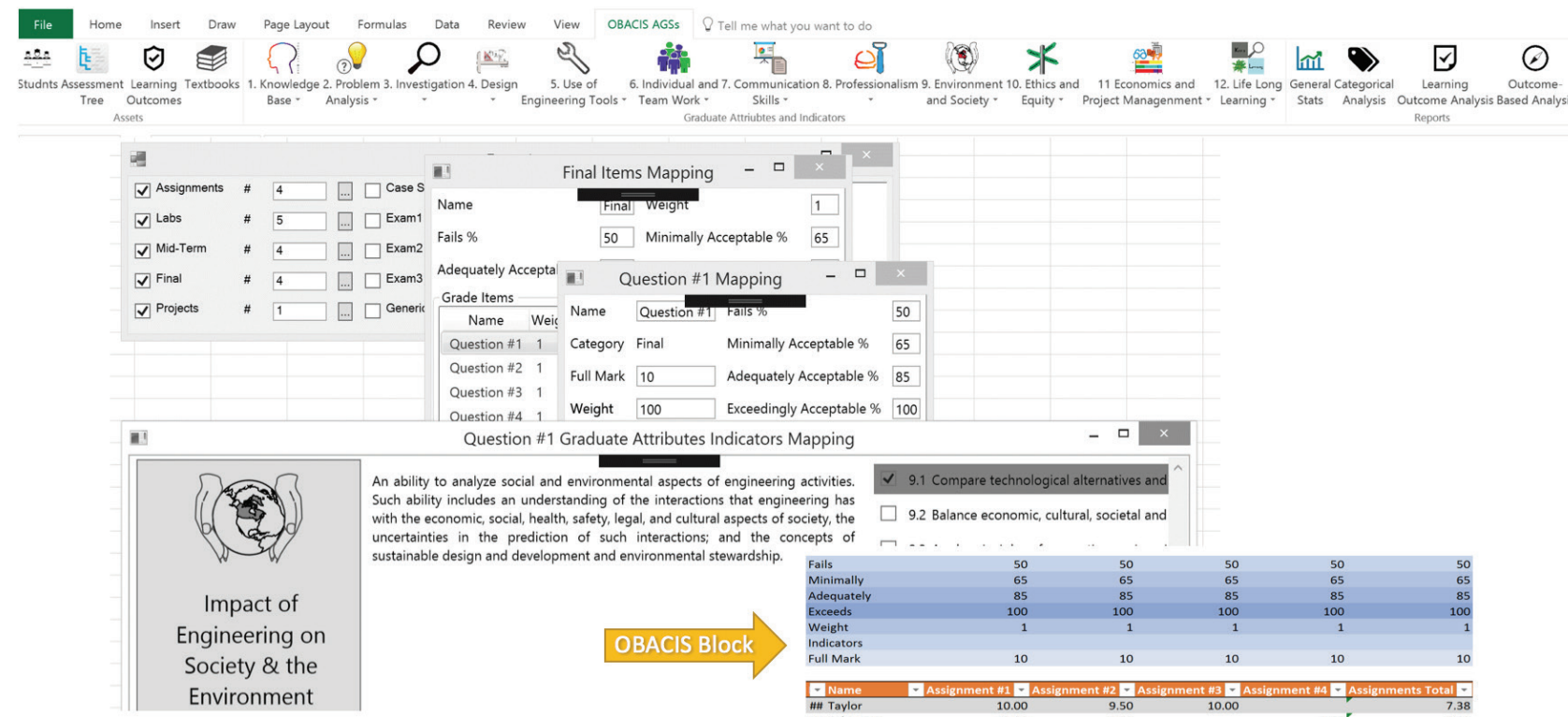

$\square 9.2$ Balance economic cultural, societal and
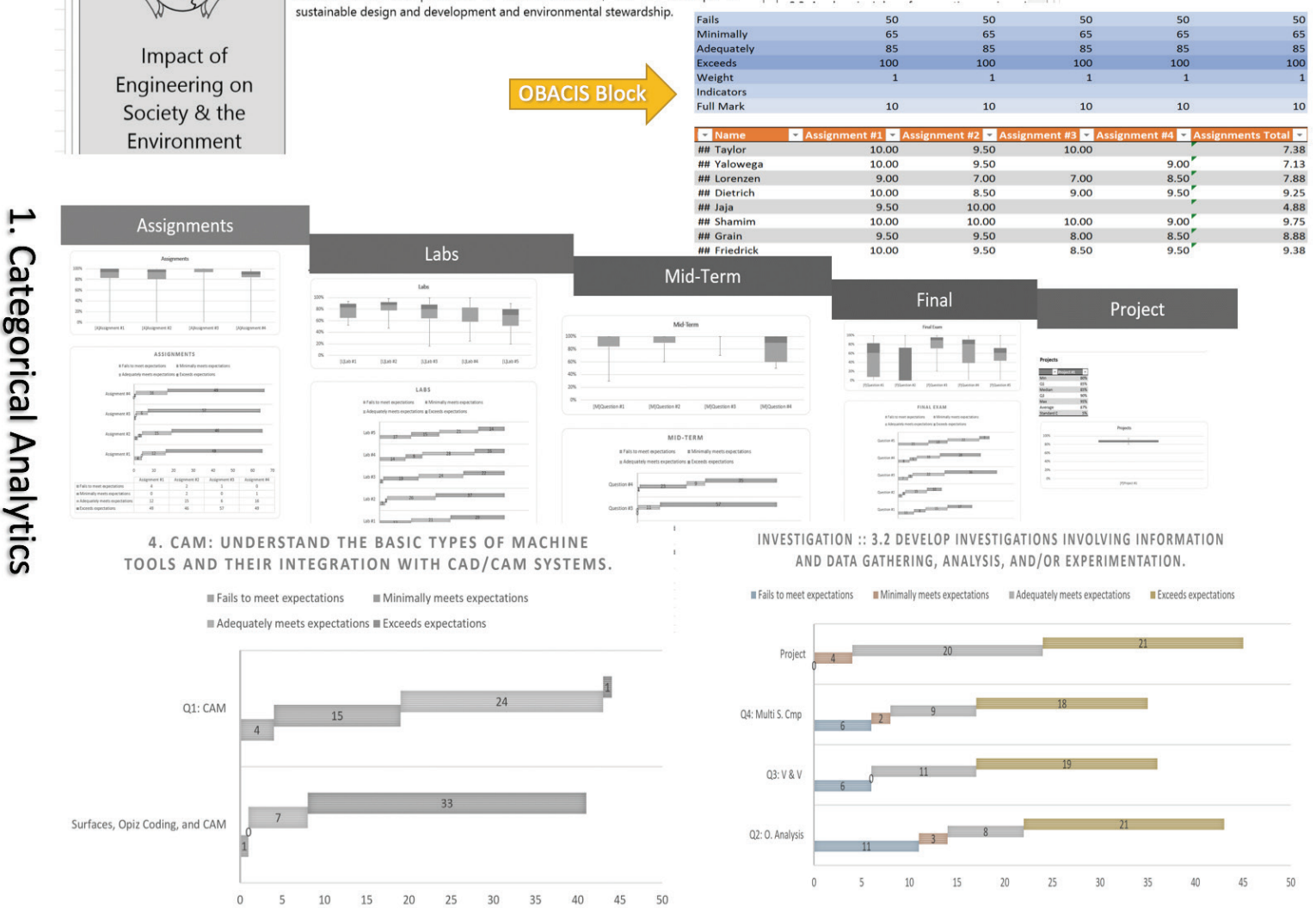

2. Learning Outcomes Analysis

\section{Graduate Attributes Analysis}

Figure 7: OBACIS AGS and The Tri-Reporting System 
ENIN 331 and ENIN 444, and then ENIN 430 in the Winter 2016. The course evaluations I got were historical records, and students comments were unheard of.

The DDCI system is designed to analyze the students' performance from 3 different perspectives:

1. Categorical Performance Analysis (CPA): all the assessment elements conducted throughout the course are analyzed statistically in order to identify the gaps and weaknesses that should be addressed in the following teaching semester(s). The focus in this part is on course components or categories.

2. Learning Outcomes Analysis (LOA): in this part, the course learning outcomes are mapped to different course grade items and analyzed from that perspective.

3. Outcome-Based Assessment Analysis (OBAA): in this part, some course items are mapped to OBA indicators and analyzed from that perspective.

Using the data analytics, we can test what's taught using CPA, What is learned using LOA, and what the Outcomebased accreditation or the market need using OBAA.

\subsection{OBACIS AGS}

The Auto Grading Sheets is double purpose tool that was developed to cut down the time of grade compilation by an order of magnitude. When used for the first time, I managed to cut down the grade compilation by 1 or 2 days to just one or two hours. The robustness of grading has been improved radically as well. For further details of the AGS system the interested readers are referred to OBACIS III paper at CEEA 17 [7]. OBACIS AGS is in service since winter 2015.

\section{TOUCH-IT AND THE UNIFIED COURSE DESIGN}

Touch-It is a powerpoint add-in that was developed in the fall of 2015 to cut the course development cycle of new courses to less than three weeks and upgrade the older ones in a week or two, see Figure 8 . The objective was to implement all the best practices related to course lectures design and provide the same unified lecture design across all my courses regardless of the course content, the original textbook, the course level: graduate or undergraduate. Some students classified my notes as 5 stars notes, thanks to the unified design and the long series of practices that have been integrated in one framework and populated across all my courses using Touch-it.

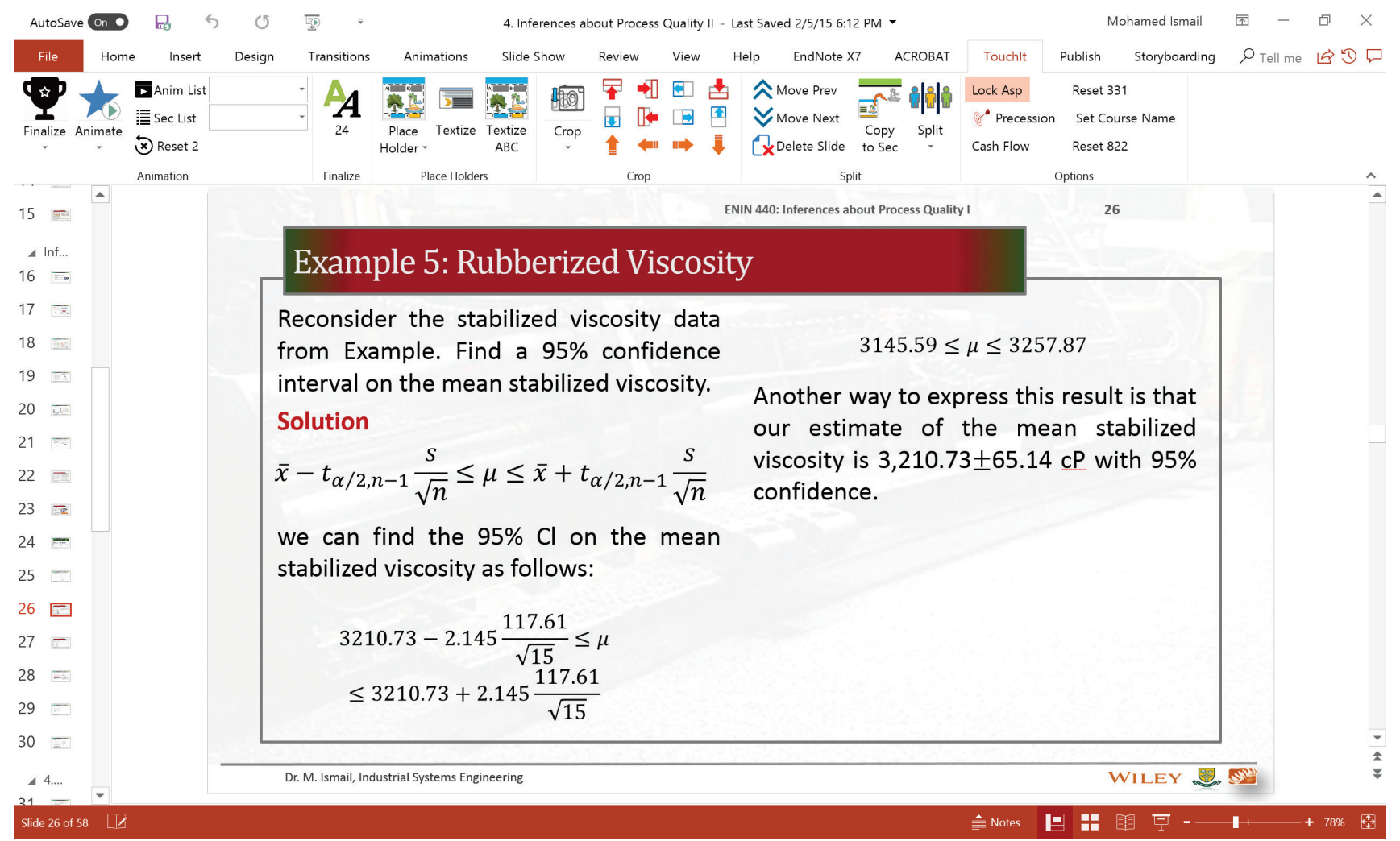

Figure 8: Touch-it: A PowerPoint Add-in that enabled the unified course design principle and implementing all best practices across all my courses. The tool was very useful to cut down the new course development cycle to 3 weeks and upgrade the older ones in just 1 week or 2. 


\section{SUMMARY AND CONCLUSIONS}

In this paper, a progressive teaching and learning experience developed by the author throughout his teaching career was presented. The process can be abstracted in a double loop continuously improving 5 -step process. The process has two iterative loops: the first for analyzing the course at hand and developing the course offering; the second is for course delivery and continuous review. Over time courses could be improved in two different ways: incrementally or radically. Depending on the real-life experience both courses of actions could be possible. The framework developed to implement the double loop process and long a good number of best practices were shared. Some advanced tools for data-driven course improvement and grade compilation were presented as well; Having those tools are not essential for applying the progressive teaching and learning methodology and framework. The experience shared demonstrate that teaching and learning is an iterative process and achieving the best performance might take a long series of actions, adaptations, time and a lot of effort to achieve peak performance.

\section{REFERENCES}

1. Ismail, M.A., Change-Ready Manufacturing Planning and Control Systems and Progressive Modeling: Vision, Principles, and Applications, in Industrial and Manufacturing Systems Engineering. 2011, University of Windsor: : Windsor, Ontario, Canada.

2. Ismail, M.A. and H. ElMaraghy, Progressive modeling-An enabler of dynamic changes in production planning. CIRP Annals Manufacturing Technology, 2009. 58(1): p. 407412.

3. (CEAB), C.E.A.B., Questionnaire for Evaluation of an Engineering Program 2016.

4. Kaupp, J. and B. Frank. EGAD National Snapshot Survey: Change, Progress and Improvement. in Canadian Engineering Education Association (CEEA16) 2016. Halifax, Nova Scotia

5. Kaupp, J., B. Frank, and C. Watts. Evaluation of software tools supporting outcomes-based continuous program improvement processes in CEEA Canadian Engineering Education Conference, CEEC13 Montreal, QC

6. Ismail, M., OBACIS: Outcome Based Analytics and Continuous Improvement System, in Canadian Engineering Education Association (CEEA16). 2016.

7. Ismail, M., OBACIS Accreditation and Grading Sheets (AGSs): The Xl-App, in Canadian Engineering Education Association (CEEA17). 2017. 